\title{
Development of experimentally-induced periodontitis in a Sprague Dawley rat model
}

\author{
H. Mustafa1 ${ }^{\circledR}$, A.K. Ali ${ }^{\circledR}$, C.H. Cheng ${ }^{\circledR}$, R. Radzi ${ }^{\circledR}$, L.S. Fong ${ }^{\circledR}$, N.M. Mustapha3 ${ }^{\circledR}$, H.O. Dyary ${ }^{1}$ \\ ${ }^{1}$ College of Veterinary Medicine, University of Sulaimani, Sulaymaniyah, ${ }^{2}$ College of Veterinary Medicine, University of \\ Mosul, Mosul, Iraq, ${ }^{3}$ Faculty of Veterinary Medicine, University Putra Malaysia, Selangor, Malaysia
}

\begin{tabular}{l} 
Article information \\
\hline Article history: \\
Received September 20, 2020 \\
Accepted February 27, 2021 \\
Available online October 1,2021 \\
\hline Keywords: \\
Alveolar bone \\
Periodontitis \\
Porphyromonas gingivalis \\
Lipopolysaccharide \\
\\
\hline Correspondence: \\
H. Mustafa \\
hana.mustafa@univsul.edu.iq
\end{tabular}

\begin{abstract}
Periodontitis is a common inflammatory disease that leads to the degradation of periodontium and results in alveolar bone loss. The development of a suitable animal model of periodontitis is a prerequisite to understanding better the mechanisms that underly this disease. This study evaluated periodontal disease induction via retentive ligature, intragingival injection of lipopolysaccharide (LPS), and their combination in a rat model. Seventy-two Sprague Dawley rats were divided into four groups. The first group (control) did not receive any treatment. The second group underwent the application of $4 / 0$ nylon ligature around the second maxillary molars. The third group was treated with an intragingival injection of Porphyromonas gingivalis LPS into the palatal mucosa of the second maxilla molars, and the fourth group was treated with a combination of ligature and LPS injection (ligature-LPS). Morphological changes in the gingival tissues were evaluated after 7, 14, and 30 days of treatment. Significant degenerative changes were observed in the periodontal tissues and alveolar bone in the third and fourth groups, which were evident as early as seven days. The lesions remained until 14 days and declined with time in the third and fourth groups. The changes induced by ligature and ligature-LPS were not different. Injection with LPS alone resulted in minimal increases in the Gingival and Plaque Indices. The ligature technique induced periodontal disease successfully, more effective than the injection of LPS. The combination of ligature with LPS injection added no significant effect compared to ligature alone.
\end{abstract}

DOI: 10.33899/ijvs.2021.128422.1573, (CAuthors, 2021, College of Veterinary Medicine, University of Mosul.

This is an open access article under the CC BY 4.0 license (http://creativecommons.org/licenses/by/4.0/).

\section{Introduction}

Periodontal disease is a major multifactorial oral disorder in humans, mainly caused by bacterial plaque deposition on the periodontium (1). The disease can be graded according to the degree of change in the gums and teeth from mild plaque and gingivitis [score 1] to gingival recession and degradation of the periodontal ligament [score 2] to significant inflammation and loss of teeth [score 3] (2). Many risk factors are involved in periodontitis pathogenesis in animals, such as breed, sex, age, diet, bedding, water, weight, zinc deficiency, and stress (3). Various animal models have been used to inquire into the mechanism of periodontal disease and the host-bacterial interaction, such as primates, dogs, pigs, ferrets, rabbits, rats, and mice (4). Rodents, particularly rats, are suitable models for experimental periodontal research because of their low cost and ease of handling (5).

Dental caries seldom occurs naturally in rodents due to microflora, pH, and diet (6). However, inoculation of Porphyromonas gingivalis and Actinobacillus actinomycetemcomitans, or their pathogenic products such as lipopolysaccharide (LPS), has been described to induce periodontitis in rats. The ligature of the dentogingival area has also been attempted to allow the accumulation of subgingival microorganisms. In the mouse, the ligature 
model could result in alveolar bone loss within a short period (7). Intra-gingival injection of LPS derived from $P$. gingivalis could also induce periodontal inflammation and bone resorption in experimental animals. However, to induce the same lesion, this method may need a longer time $(8,9)$. A combination of ligature and inoculation of $P$. gingivalis has been reported to induce alveolar bone loss in the rat model (10). The combination of ligature with a pathogenic product, such as lipopolysaccharide from $P$. gingivalis, which would accelerate the process, is not well described. We hypothesize that a combination of ligature and injection of LPS would induce periodontal disease in a shorter time compared to using either ligature or LPS alone. Hence, this study aimed to find the best model of periodontal disease production in the shortest time. We compared the morphological changes of periodontal disease induced by ligature, injection of LPS, and a combination of ligature-LPS injection in the Sprague Dawley rat model.

\section{Materials and methods}

\section{Animals and experimental protocol}

Seventy-two male, 8-9 weeks old Sprague-Dawley rats, weighing 292-360 g, were used in this study. All rats were purchased from the Animal Resource Unit and kept at the Animal Research Facility, Faculty of Veterinary Medicine, University Putra Malaysia. The rats were acclimated for one week before starting the experiment by confining each pair in an $800 \mathrm{~cm}^{2}$ plastic cage of $17 \mathrm{~cm}$ height. The room was well ventilated, and the temperature was regulated at $22 \pm$ $2^{\circ} \mathrm{C}$. A 12-hour light-dark system was followed with lights on at 7:00 p.m. Standard laboratory rat chow pellets and filtered tap water were provided ad libitum (11). All rats were healthy based on physical examination. The Animal Care and Use Committee at University Putra Malaysia approved the experimental protocol (approval number UPM/IACUC/AUP-R048/2016). Rats were divided into groups C, L, LPS, and L-LPS. Group C served as the control with no treatment except for examination under general anesthesia. Group L was treated with the bilateral placement of $4 / 0$ nylon ligature on the second upper molar teeth. Group LPS was intragingivally injected with $P g$-LPS. Group L-LPS was treated with a combination of $4 / 0$ nylon ligature and intragingival injection of $P g$-LPS.

\section{Ligature placement}

The ligature procedures were performed under general anesthesia, induced by an intraperitoneal injection of a mixture of ketamine $50 \mathrm{mg} / \mathrm{kg}$ and xylazine $5 \mathrm{mg} / \mathrm{kg}$. Bilateral placement of ligatures on the periodontium of the second upper molar teeth was performed using the surgeon's knots and sterile 4/0 nylon suture Ethilon 4/0. W1620, 2018, USA. This procedure was done in the second and fourth groups. Isoflurane was used for maintaining anesthesia at concentrations of $2-3 \%$ in $100 \%$ oxygen $1.5-2.0 \mathrm{~L} / \mathrm{min}$ by using a small nose cone modified from a circuit adaptor and strips of the elastic bandage. The anesthesia lasted less than one hour in all groups (12). The ligatures were examined twice weekly until the rats were sacrificed at the end of the experiment.

\section{Injection of $P g$-LPS into the gingiva}

A purified preparation of $P g$-LPS was purchased from Invivo Gen Inc. (San Diego, CA, USA). A concentration of $1 \mathrm{mg} / \mathrm{mL}$ of $P g$-LPS was prepared using normal saline as the diluent. Then, $10 \mu \mathrm{L}$ of the preparation was injected into the subgingival tissue. The palatal side of the second maxillary molars was used as the injection site. A microsyringe (Hamilton 60330,701RN $10 \mu$ l SYR USA) was used in the procedure.

\section{Animal sacrifice and analyses}

Six rats from each group were sacrificed at 7, 14 and 30 days of the experiment. The rats were euthanized with an intraperitoneal dose of pentobarbitone $200 \mathrm{mg} / \mathrm{kg}$ (12). The macroscopic properties of the second maxillary molars and associated palatal gingival tissues were evaluated. Parameters such as gingival tissue appearance and structure, gingival color change, accumulation of plaque, tooth mobility, and gingival tissue bleeding were observed. The morphological evaluations were scored based on a modification of the Gingival Index (GI) and Plaque Index (PI) initially introduced by Loe and Silness in 1963 and 1964, respectively (13). The GI and PI could be scored based on all teeth or selected teeth and all sides or a selected side of the gingival tissues. In this study, scorings were based on the visual assessment of both the second maxillary molars' lingual side. Descriptions of the modified GI and PI are summarized in Tables 1 and 2 .

Table 1: Gingival Index (GI)

\begin{tabular}{cl}
\hline Score & Criteria \\
\hline 0 & No inflammation \\
\hline 1 & $\begin{array}{l}\text { Mild inflammation with a slight change in color, } \\
\text { slight edema, no bleeding on palpation }\end{array}$ \\
2 & $\begin{array}{l}\text { Moderate inflammation with moderate glazing and } \\
\text { redness, bleeding on palpation }\end{array}$ \\
\hline 3 & $\begin{array}{l}\text { Severe inflammation with marked red ulceration, a } \\
\text { tendency to spontaneous bleeding }\end{array}$ \\
\hline
\end{tabular}

Table 2: Plaque Index (PI)

\begin{tabular}{cl}
\hline Score & Criteria \\
\hline 0 & No plaque \\
1 & $\begin{array}{l}\text { Moderate aggregation of deposits within the } \\
\text { gingival pocket, on the gingival border or adjacent } \\
\text { tooth surface, or both }\end{array}$ \\
\hline 2 & $\begin{array}{l}\text { Copiousness of soft matter inside the gingival } \\
\text { pocket, or on the tooth and gingival margin, or both }\end{array}$ \\
\hline
\end{tabular}




\section{Statistical analysis}

Statistical analysis was performed using IBM SPSS software, and differences were considered significant at $\mathrm{P}<0.05$. The morphological evaluation results were compared using the non-parametric Kruskal-Wallis test, followed by a post hoc Bonferroni correction (14).

\section{Results}

\section{Morphological evaluation}

The experimental models of periodontal disease were induced successfully in all four groups of different periods (Figure 1).
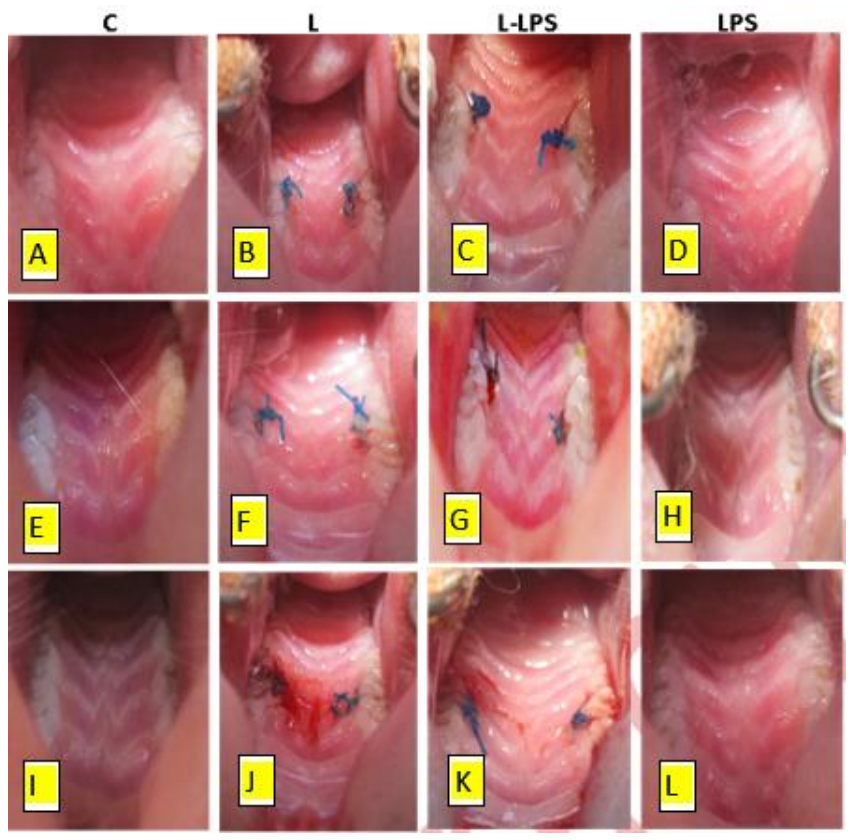

Figure 1: Representative gross morphology of group $\mathrm{C}=$ Control, $\mathrm{L}=$ ligature group, L-LPS = ligature with LPS injection group, LPS $=$ lipopolysaccharide injection group at day 7 (A, D, G, J), 14 (B, E, H, K) and 30 (C, F, I, L). The second molar's gingival tissue in groups L and L-LPS at days 7, 14 and 30 showed swelling, redness, and plaque around the nylon thread and bleeding upon palpation. Group LPS injection at day 30 has mild plaque around the teeth without signs of inflammation. No change was observed in the control group at all times.

\section{Gingival index score}

The ligature and ligature-LPS groups showed significantly higher gingival index (GI) scores than the control throughout days 7, 14, and 30 (Figure 2). The GI tended to be decreased by day 30 in both ligature and ligature-LPS groups $(\mathrm{P}=$ 0.001). Injection with LPS alone revealed slightly higher GI scores at days 14 and 30, but a statistical difference from control could not be demonstrated. Representative gross appearance of all groups at days 7, 14 and 30 (Figure 3).

\section{Plaque index score}

The L and L-LPS groups showed significantly higher PI scores than the control group throughout days 7, 14, and 30 (Figure 3). The plaque index tended to be reduced by day 30 in both $\mathrm{L}$ and L-LPS groups $(\mathrm{P}=0.001)$. Injection with LPS alone increased slightly at days 14 and 30, but the statistical difference from control was not observed.
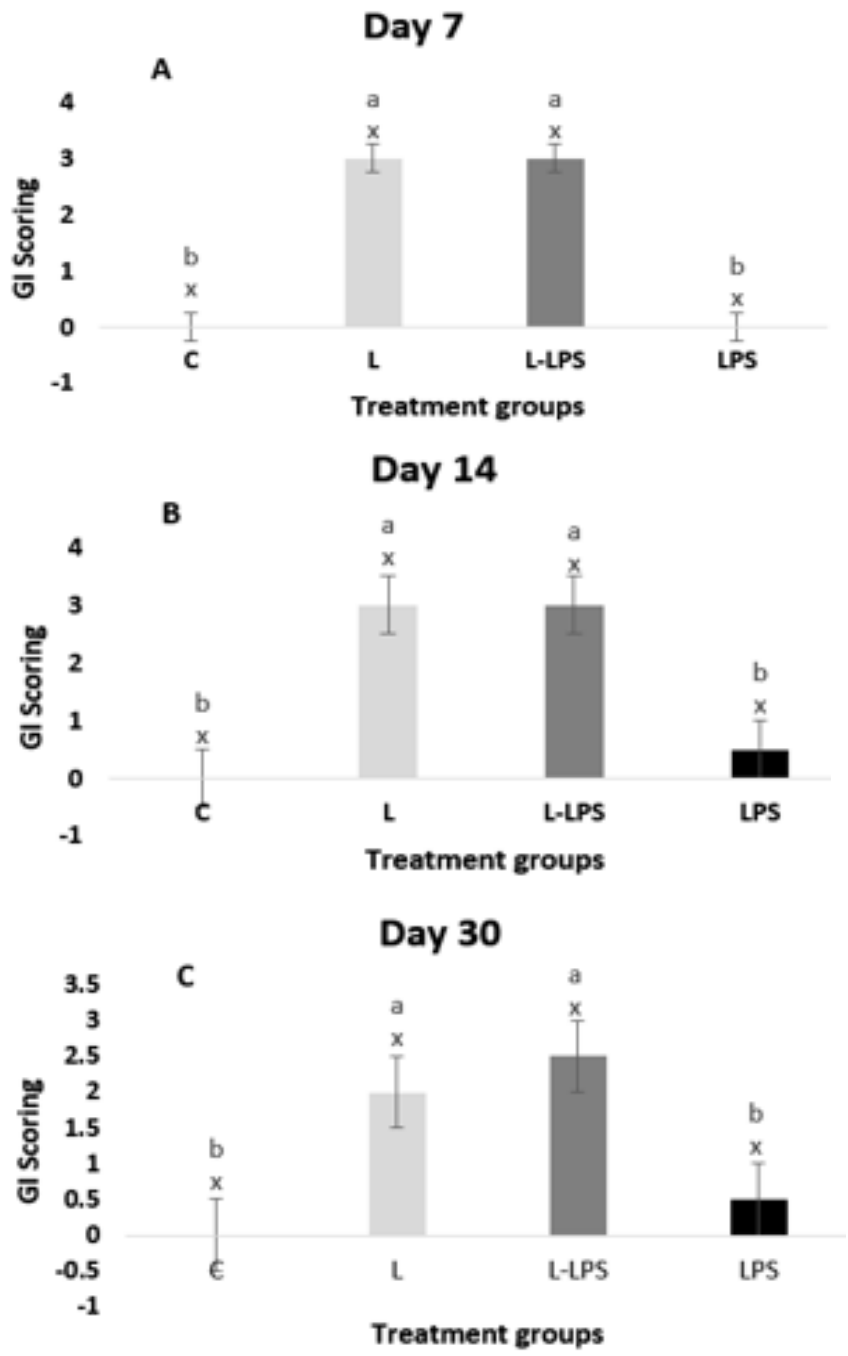

Figure 2: Gingival index scores of four different groups. $\mathrm{C}=$ control, $\mathrm{L}=$ ligature, L-LPS = ligature with LPS injections, LPS $=$ Lipopolysaccharide at three different times $\mathrm{A}=$ Day 7, B = Day 14, C = Day 30. Results are expressed as the median +/-interquartile range. Different alphabet denotes significant difference, $\mathrm{P}<0.05$. abc: different alphabets show differences between the treatment groups; xyz: different alphabets show differences over time within the treatment groups. Statistics used is the Kruskal-Wallis test, followed by a post hoc multiple comparison test with Bonferroni correction. 
A

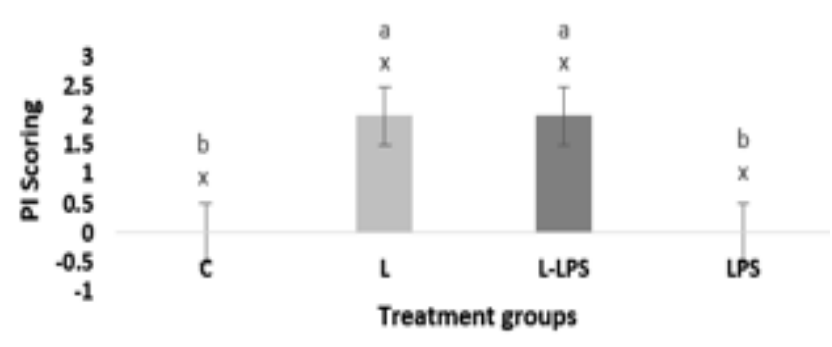

B

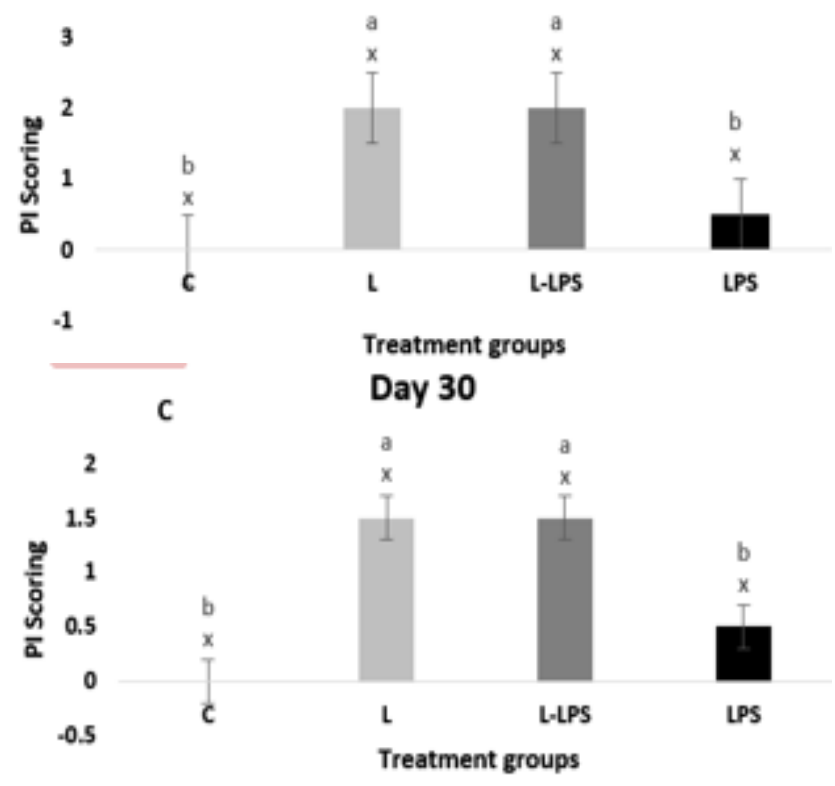

Figure 3: Plaque index scores of four different groups; $\mathrm{C}=$ control, $\mathrm{L}=$ ligature, L-LPS = ligature with LPS injections, LPS $=$ Lipopolysaccharide injections at three different times $\mathrm{A}=$ day $7, \mathrm{~B}=$ day $14, \mathrm{C}=$ day 30 . Results are expressed as the median + -interquartile range. Different alphabet denotes significant difference, $\mathrm{P} \leq 0.05$; abc: different alphabets show differences between the treatment groups; xyz: different alphabets show differences over time within the treatment groups. Statistics used is the Kruskal-Wallis test, followed by a post hoc multiple comparison test with Bonferroni correction.

\section{Discussion}

The development of an easy-to-accomplish and economic animal model to stimulate periodontitis is essential to study periodontal alterations following the execution of different therapeutic approaches $(15,16)$. The present study compared the morphological changes in the periodontium after inflammation was induced by ligature, gingival injection of $P g$-LPS, and a combination of these methods in a rat model.
The current study results revealed that significant degenerative changes in the gingival tissue could be stimulated as early as seven days after using ligature and a combination of ligature-LPS.

Hence, acute periodontitis can be produced in Sprague Dawley rats by the ligature method. In contrast, only mild inflammatory modifications were noticed after injection of $P g$-LPS into the gingiva, according to the control.

In our model, a $4 / 0$ nylon suture was used around both maxillary second molars. Although this method is more challenging than ligature placement on the first molar or the incisor, no slipped ligature incidence was seen.

This study showed that using ligature alone is efficacious to enhance acute periodontitis in the Sprague Dawley rat. This method created significant morphological alterations when compared to control and LPS-treated groups.

This study's suture material caused mechanical injury to the dentogingival area and played as a plaque retentive device. The ligature and ligature-LPS groups showed significantly higher gingival index (GI) scores than the control throughout days 7,14 , and 30 .

Gingival index tended to be decreased by day 30 in both ligature and ligature-LPS groups. Injection with LPS alone revealed slightly higher GI scores at days 14 and 30, but a statistical difference from control could not be demonstrated. Currently, the GI and PI scoring systems have been used in experimental animal models.

Orbak et al. (17) used the GI and PI scoring systems to study the alterations of oral and periodontal tissues in zincdeficient rats compared to zinc-sufficient rats.

The amount of $P g$-LPS and injection frequency may not have been adequate to develop degenerative inflammatory reactions in this model. Hence, it might be more useful to use higher doses of $P g$-LPS with increased frequencies.

Dumitrescu et al. (18) reported that the gingival tissue in rats is tightly bound, which might not expand to adapt for a volume of $10 \mu \mathrm{g}$. Consequently, some of the LPS may leak from the injection site. As a result, the application of LPS at a higher concentration might be implemented to compensate for the loss (19).

\section{Conclusion}

Acute periodontitis could be created using the ligature method in Sprague Dawley rats. Injection of $P g$-LPS into the gingiva produces just mild inflammatory changes. The outcomes of this study offer the basis for future preclinical preventive or treatment models of periodontal disease.

\section{Acknowledgments}

The authors thank the University of Sulaimani, University Putra Malaysia, and University of Mosul for providing the facilities to accomplish this study. 


\section{Conflict of interest}

The authors declare no conflict of interest.

\section{References}

1. Petersen PE. Challenges to improvement of oral health in the $21^{\text {st }}$ century-the approach of the WHO Global Oral Health Programme. Int Dent J. 2004;54:329-343. DOI: 10.1111/j.1875-595X.2004.tb00009.X

2. How KY, Song KP, Chan KG. Porphyromonas gingivalis: An overview of periodontopathic pathogen below the gum line. Front Microbiol. 2016;7:53. DOI: 10.3389/fmicb.2016.00053

3. Duarte PM, Tezolin KR, Figueiredo LC, Feres M, Bastos MF. Microbial profile of ligature-induced periodontitis in rats. Arch Oral Biol. 2010;55:142-147. DOI: 10.1016/j.archoralbio.2009.10.006

4. Polak D, Wilensky A, Shapira L, Halabi A, Goldstein D, Weiss EI, Houri-Haddad Y. Mouse model of experimental periodontitis induced by Porphyromonas gingivalis/Fusobacterium nucleatum infection: bone loss and host response. J Clin Periodontol. 2009;36:406-410. DOI: 10.1111/j.1600-051X.2009.01393.X

5. Oz HS, Puleo DA. Animal models for periodontal disease. BioMed Res Int. 2011;2011. DOI: 10.1155/2011/754857

6. Wiggs RB, Lobprise HB. Dental disease in rodents. J Vet Dent. 1990;7:6-8. DOI: 10.1177/089875649000700305

7. de Molon RS, de Avila ED, Boas Nogueira AV, Chaves de Souza JA, Avila-Campos MJ, de Andrade CR, Cirelli JA. Evaluation of the host response in various models of induced periodontal disease in mice. $\mathbf{J}$ Periodontol. 2014;85:465-477. DOI: 10.1902/jop.2013.130225

8. Fujita A, Nakata T, Umeda M, Masuzaki H, Sawai H. Increased expression of 11ß-hydroxysteroid dehydrogenase type 1 in experimental periodontitis induced by lipopolysaccharide from Porphyromonas gingivalis. OJST. 2017;7:429-438. DOI: 10.4236/ojst.2017.710037.9

9. Muhamad SA, Ali OJ, Abbas BT, Marif HF, Sleman RR, Ali BM, Raza DA, Hama Ali HH, Ali GM. A retrospective study of fracture cases managed in the veterinary teaching hospital; 181 cases (2014-2018). Iraqi J Vet Sci. 2020. DOI: 10.33899/ijvs.2020.126228.1266

10. Storrer CLM, Deliberador TM, Giovanini AF, Crivellaro V, Zielak JC, Romito GA. Effect of alendronate on the progression of periodontitis induced by Porphyromonas gingivalis and Fusobacterium nucleatum: a study in rats. Clin Oral Investig. 2016;20:2565-2573. DOI: 10.1007/s00784-016-1769-4

11. Jahandideh A, Abedi G, Akbarzadeh A. Histopathological assessment of nano n-acetyl cysteine effect on postoperative adhesion in rats. Iraqi J Vet Sci. 2021;35:589-597. DOI: 10.33899/ijvs.2020.126857.1400

12. Atarbashe RK, Abu-Raghif A. Comparative treatment of induced ulcerative colitis in male rat model by using cinnarizine and sulfasalazine. Iraqi J Vet Sci. 2020;34:465-472. DOI: 10.33899/ijvs.2019.126170.1254

13. Chhibber A, Agarwal S, Yadav S, Kuo CL, Upadhyay M. Which orthodontic appliance is best for oral hygiene? A randomized clinical trial. Am J Orthod Dentofacial Orthop. 2018;153:175-183. DOI: 10.1016/j.ajodo.2017.10.009

14. Verhulst MJ, Teeuw WJ, Bizzarro S, Muris J, Su N, Nicu EA, Nazmi $\mathrm{K}$, Bikker FJ, Loos BG. A rapid, non-invasive tool for periodontitis screening in a medical care setting. BMC Oral Health. 2019; 19:1-14. DOI: $10.1186 / \mathrm{s} 12903-019-0784-7$

15. Li D, Feng Y, Tang H, Huang L, Tong Z, Hu C, Chen X, Tan J. A simplified and effective method for generation of experimental murine periodontitis model. Front Bioeng Biotechnol. 2020;8:444. DOI: 10.3389/fbioe. 2020.00444

16. Jiang $\mathrm{H}, \mathrm{Li}$ Y, Ye C, Wu W, Liao G, Lu Y, Huang P. Changes in advanced glycation end products, beta-defensin-3, and interleukin-17 during diabetic periodontitis development in rhesus monkeys. Exp Biol Med. 2018;243:684-694. DOI: 10.1177/1535370218766512

17. Orbak R, Kara C, Özbek E, Tezel A, Demir T. Effects of zinc deficiency on oral and periodontal diseases in rats. J Periodontal Res. 2007;42:138143. DOI: $10.1111 /$ j.1600-0765.2006.00939.x
18. Dumitrescu AL, Abd El-Aleem S, Morales-Aza B, Donaldson LF. A model of periodontitis in the rat: Effect of lipopolysaccharide on bone resorption, osteoclast activity, and local peptidergic innervation. J Clin Periodontol. 2004:31:596-603. DOI: $10.1111 / \mathrm{j} .1600$ 051X.2004.00528.X

19. Takamori A, Yoshinaga Y, Ukai T, Nakamura H, Takamori Y, Izumi $\mathrm{S}$, Shiraishi C, Hara Y. Topical application of glycyrrhetinic acid in the gingival sulcus inhibits attachment loss in lipopolysaccharide-induced experimental periodontitis in rats. J Periodontal Res. 2018;53:422-429. DOI: $10.1111 /$ jre.12529

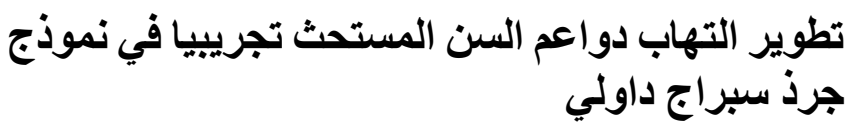

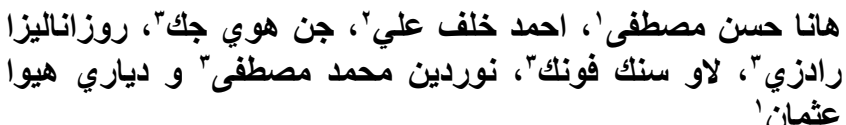

'كلية الطب البيطري، جامعة السليمانية، السليمانية، بكلية الطب

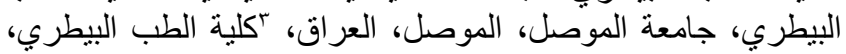
جامعة بونر ا الماليزية، كو الا لامبور، الموهي ماليزيا

الخلاصة

التهاب دواعم السن هو مرض التهابي شائع يؤدي إلى تدهور اللثة

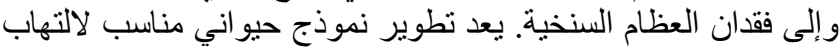

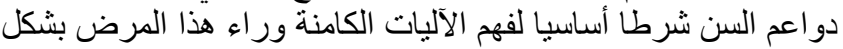

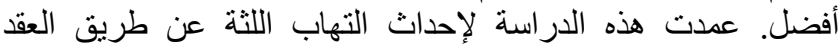

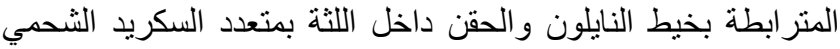

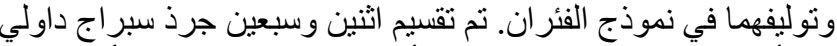
إلى أربع مجموعات. المجموعة الأولى (السيطرة) لم تتلق أي عاني علاج.

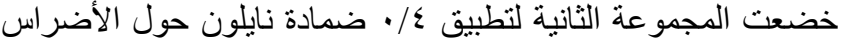

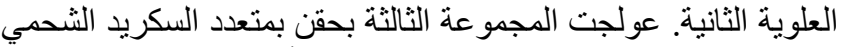
داخل اللثة في الغثاء المخاطي الحنكي للأضر اس العلوية العية الثانية،

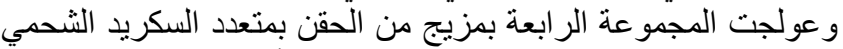

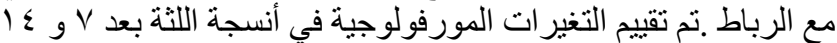

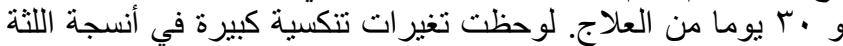

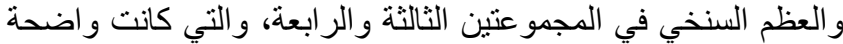

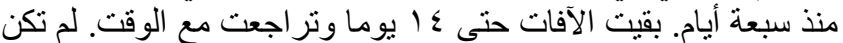
التغيير ات التي أحدثها الرباطو الرباط مع متعدد الأب السكريد الثحمي مختلفة.

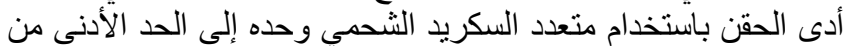

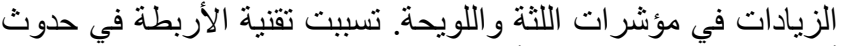

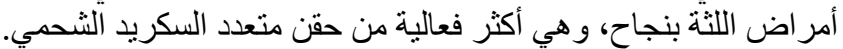
لم يضف الجمع بين الأربطة وحقن متعدد السكريد الثحمي أي تأثير معنوي. 